\title{
RESEARCH
}

Open Access

\section{Administration of cytokine-induced myeloid-derived suppressor cells ameliorates renal fibrosis in diabetic mice}

Ching-Chuan Hsieh ${ }^{1,24^{*}}$ (D), Chun-Liang Lin ${ }^{3,4}$, Jie-Teng He², Meihua Chiang², Yuhsiu Wang ${ }^{2}$, Yu-Chin Tsai ${ }^{2}$, Chien-Hui Hung ${ }^{1}$ and Pey-Jium Chang ${ }^{1,4}$

\begin{abstract}
Background: Diabetes is a proinflammatory state. Fibrosis of the renal glomerulus is the most common cause of end-stage renal disease. Glomerulosclerosis is caused by the accumulation of extracellular matrix (ECM) proteins in the mesangial interstitial space. Mesangial cells are unique stromal cells in the renal glomerulus that form the vascular pole of the renal corpuscle along with the mesangial matrix. Myeloid-derived suppressor cells (MDSCs) are heterogeneous immature myeloid cells that rapidly expand to regulate host immunity during inflammation, infection, and cancer. High concentrations of granulocyte-macrophage colony-stimulating factor (GM-CSF) alone or in combination with other molecules represent the most common ex-vivo protocol for differentiating MDSCs from bone marrow or from peripheral blood mononuclear cells. In this study, we analyzed and characterized the functions of MDSCs under the influence of mouse mesangial cells (MMCs) in a hyperglycemic environment and investigated whether cytokine-induced MDSCs ameliorated renal glomerulosclerosis in diabetic mice.
\end{abstract}

Methods: Cytokine-induced MDSCs were propagated from bone marrow cells cultured with mouse recombinant GM-CSF, IL-6, and IL-1 $\beta$. Diabetic mice were induced with streptozotocin (STZ) and maintained at a blood glucose concentration exceeding $350 \mathrm{mg} / \mathrm{dl}$. The ECM of the renal cortex and fibronectin expression of MMCs were analyzed through immunohistochemistry and western blotting. Arginase 1 and inducible NO synthase expressions of MDSCs were evaluated using quantitative reverse-transcriptase PCR. Cytokines released from MMCs were examined using a cytokine array assay.

Results: MDSCs in the diabetic mice were redistributed from the bone marrow into peripheral organs. An increase in fibronectin production was also observed in the renal glomerulus. MMCs in vitro produced more fibronectin and proinflammatory cytokines, such as macrophage inflammatory protein-2, RANTES, and stromal-cell-derived factor-1, under hyperglycemic conditions. The adoptive transfer of cytokine-induced MDSCs into STZ-induced mice normalized the glomerular filtration rate to reduce the kidney to body weight ratio and decrease fibronectin production in the renal glomerulus, ameliorating renal fibrosis. These results demonstrate the anti-inflammatory properties of cytokineinduced MDSCs and offer an alternative immunotherapy protocol for the management of diabetic nephropathy.

Conclusions: The application of cytokine-induced MDSCs provides a promising treatment for renal fibrosis and the prevention of diabetic nephropathy.

Keywords: Myeloid-derived suppressor cells, Immunotherapy, Fibronectin, Diabetic nephropathy

\footnotetext{
* Correspondence: jeffrey570404@gmail.com

${ }^{1}$ Graduate Institute of Clinical Medical Sciences, College of Medicine,

Chang-Gung University, Taoyuan, Taiwan

${ }^{2}$ Department of Surgery, Chang-Gung Memorial Hospital, 6, Sec. West

Chia-Pu Road, Pu-Zi City, Chiayi County 613, Taiwan

Full list of author information is available at the end of the article
}

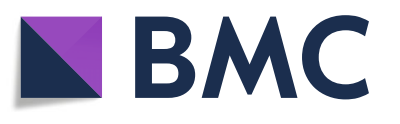

(c) The Author(s). 2018 Open Access This article is distributed under the terms of the Creative Commons Attribution 4.0 International License (http://creativecommons.org/licenses/by/4.0/), which permits unrestricted use, distribution, and reproduction in any medium, provided you give appropriate credit to the original author(s) and the source, provide a link to the Creative Commons license, and indicate if changes were made. The Creative Commons Public Domain Dedication waiver (http://creativecommons.org/publicdomain/zero/1.0/) applies to the data made available in this article, unless otherwise stated. 


\section{Background}

Type 1 diabetes (T1D) is an insulin-dependent disorder characterized by kidney failure, blindness, heart disease, and chronic ulcers [1]. Nephropathy is one of the adverse effects of diabetes and is the most common cause of end-stage renal disease worldwide [2]. Progression of diabetic nephropathy to end-stage kidney disease is mediated by a host of processes, but none is as important as the gradual, inevitable scarring of the renal glomerulus, known as glomerulosclerosis. Glomerulosclerosis in diabetic nephropathy is caused by accumulation of extracellular matrix (ECM) proteins in the mesangial interstitial space, resulting in fibrosis manifested by either diffuse or nodular changes [3]. Extraglomerular cells, such as bone marrow (BM)-derived mesangial cell progenitors [4] and macrophages [5], may contribute considerably to glomerulosclerosis in diabetic nephropathy.

Myeloid-derived suppressor cells (MDSCs) were described more than 20 years ago in patients with cancer [6-8], but their functional importance in the immune system has only recently been appreciated. In pathological conditions, such as cancer, infectious diseases, sepsis, trauma, BM transplantation, and some autoimmune disorders, a partial block in the differentiation of immature myeloid cells results in an expansion of MDSCs [9]. In mice, these cells are defined by surface expression of CD11b (Mac-1) and Gr-1 (Ly6G); however, MDSCs have still not been well characterized in humans owing to the lack of specific markers [10]. Immunoregulatory activities within MDSCs include increased production of arginase I [11], inducible NO synthase (iNOS) [12], reactive oxygen species [13, 14], and anti-inflammatory cytokines [15].

The most widely used sources of MDSCs for immunotherapy are the spleen and blood of tumor-bearing mice, but substantial safety considerations must be made in these cases [16]. High concentrations of granulocytemacrophage colony-stimulating factor (GM-CSF) alone or in combination with other molecules represent the most common ex-vivo protocol to differentiate MDSCs from $\mathrm{BM}$ or from peripheral blood mononuclear cells [17]. In this study, we analyzed and characterized the functions of MDSCs under the influence of mouse mesangial cells (MMCs) in a hyperglycemic environment. Additionally, we investigated how cytokine-induced MDSCs (cMDSCs) may ameliorate renal glomerulosclerosis in diabetic mice.

\section{Methods}

\section{Animals, cell line, and streptozotocin-induced diabetic} mice

Male C57BL/6 (B6) and BALB/c mice were purchased from the National Laboratory Animal Center (Taiwan). The mice (B6) were injected intraperitoneally with a single dose of $180 \mathrm{mg} / \mathrm{kg}$ streptozotocin (STZ). Those with blood glucose concentrations exceeding $350 \mathrm{mg} / \mathrm{dl}$ for 2 consecutive days were considered diabetic mice. All animal experiments were approved by the Institutional Animal Care and Use Committee of the Chang Gung Memorial Hospital (IACUC permit number: 2012091902) and were performed in accordance with the Animal Protection Law by the Council of Agriculture, Executive Yuan (Taiwan) and the National Research Council's Guide for the Care and Use of Laboratory Animals (USA). The MMC cell line SV40 MES 13, which was derived from ATCC CRL-1927 and obtained from the Bioresource Collection and Research Center (Taiwan), was used in this study.

\section{Culture of conventional MDSCs and cytokine-induced MDSCs}

Bone marrow cells $\left(2 \times 10^{6}\right.$ cells/well $)$ from the tibias and femurs of B6 mice were cultured in Roswell Park Memorial Institute (RPMI)-1640 medium containing 10\% fetal calf serum in the presence of mouse recombinant GM-CSF (10 ng/ml; R\&D Systems, Minneapolis, MN, USA) for 7 days. Cells that were double positive for CD11b and Gr-1 were considered MDSCs. Cytokine-induced MDSCs were propagated from BM cells cultured with mouse recombinant GM-CSF (10 ng/ml), IL-6 (10 ng/ml; R\&D Systems), and IL-1 $(10 \mathrm{ng} / \mathrm{ml}$; R\&D Systems) for 7 days. The purity of cytokine-induced MDSCs $\left(\mathrm{CD} 11 \mathrm{~b}^{+} / \mathrm{Gr}-1^{+}\right)$was more than $90 \%$ (Additional file 1: Figure S1).

\section{MMCs cocultured with MDSCs and cytokine production assay}

To test the impact of MMCs on the development of MDSCs, MMCs were added at the beginning of the MDSC culture at a MMC:BM cell ratio of 1:80. Floating cells were harvested, washed, and resuspended in RPMI-1640 medium in the presence of mouse recombinant GM-CSF $(10 \mathrm{ng} / \mathrm{ml})$ for 7 days. Cells that were double positive for $\mathrm{CD} 11 \mathrm{~b}$ and $\mathrm{Gr}-1$ were considered MDSCs. Expression of chemokines, growth factors, and immunomodulators in conditioned medium from MMCs $\left(4 \times 10^{5}\right.$ cells/well $)$ cultured at normal glucose (5 mM) or high glucose (25 mM) levels for $72 \mathrm{~h}$ was measured using a cytokine array kit.

\section{Adoptive transfer of cMDSCs into STZ-induced diabetic mice}

Cytokine-induced MDSCs $\left(1 \times 10^{7}\right.$ cells $)$ were adoptively transferred into STZ-treated diabetic mice through the pudendal vein once a week for 3 weeks until mice in each group were sacrificed on day 27. Blood sugar levels and body weight were measured twice a week until the mice were sacrificed. Blood sugar was measured from the tail tip in the untreated, STZ-treated, and cMDSC-treated 


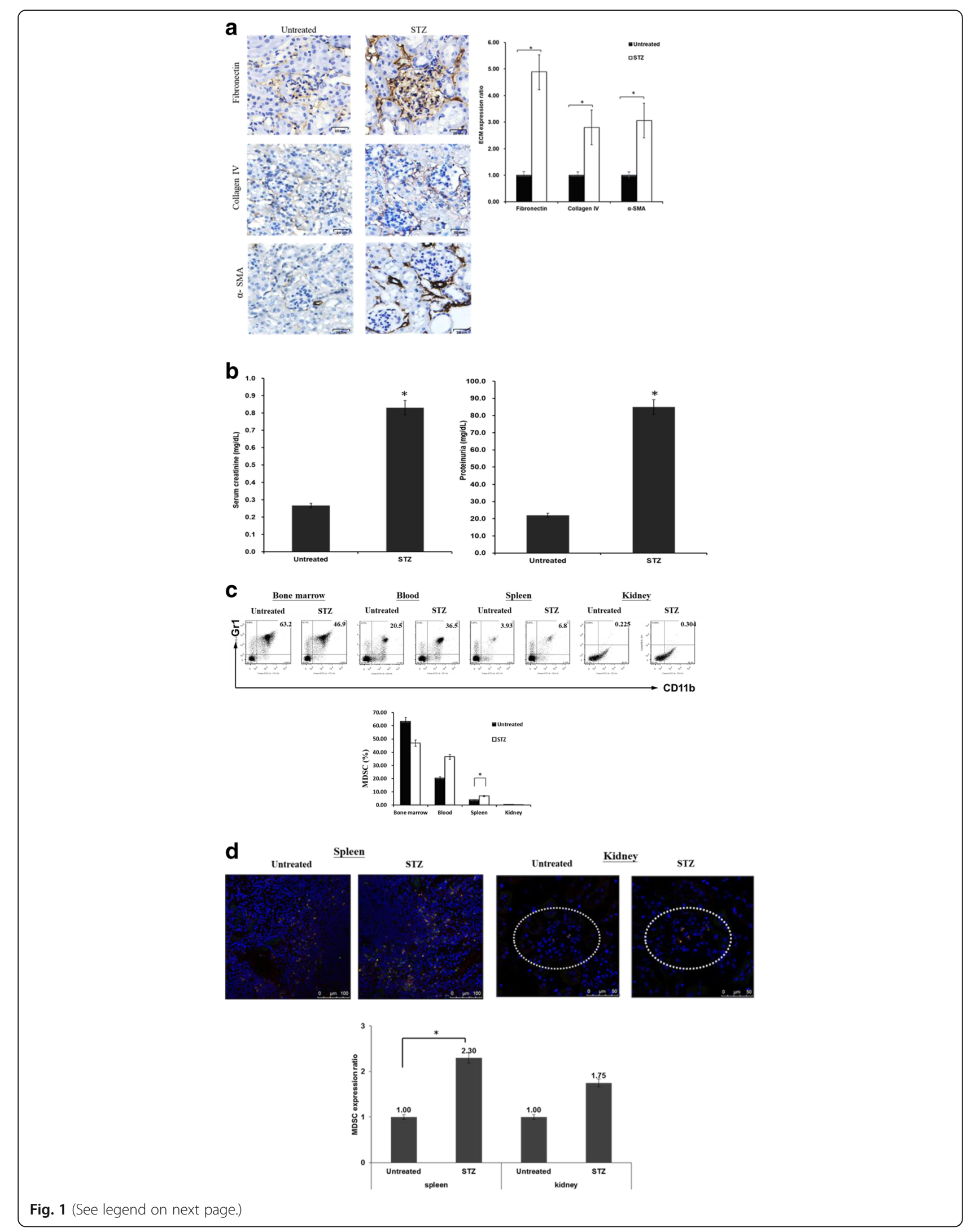


(See figure on previous page.)

Fig. 1 Renal ECM expression and MDSC distribution in STZ-treated diabetic mice. a Diabetes induced in mice using one dose of streptozotocin (STZ, $180 \mathrm{mg} / \mathrm{kg}$ ) intraperitoneally, and blood glucose levels maintained over $350 \mathrm{mg} / \mathrm{dl}$. Four weeks later, mice were sacrificed and ECM expression in kidney examined. Kidney cryostat sections histochemically stained with anti-fibronectin mAb, anti-collagen type IV mAb, or anti-alpha smooth muscle actin mAb (left panel, brown, 400x magnification). Bar graph shows quantification of differences in ECM expression of kidney between STZ-treated diabetic mice and untreated mice (right panel, ${ }^{*} P<.05$ ). b Blood and urine collected for serum creatinine and protein analyses when mice sacrificed. Level of differences in serum creatinine and proteinuria between STZ-treated diabetic mice and untreated mice $\left({ }^{*} P<.05\right)$. c MDSC ratios $\left(C D 11 b^{+} / G r-1^{+}\right)$in $B M$, blood, spleen, and kidneys of STZ-treated diabetic mice and untreated mice compared. Isolated cells were two-color stained with specific mAbs against CD11b and Gr-1 for flow analyses. Double-positive CD11b and Gr-1 cells represent MDSCS $\left({ }^{*} P<.05\right)$. d Cryostat sections of spleen and kidney from STZ-treated diabetic mice and untreated mice double-stained with anti-CD11b (green) and anti-Gr-1 (red) mAbs and evaluated under fluorescent microscope (400x magnification; upper panel). Double-positive cells counted. In total, 10 high-power fields randomly selected in each section. Data expressed as mean CD $11 \mathrm{~b}^{+} / \mathrm{Gr}-1^{+}$cells \pm 1 SD (lower panel, ${ }^{*} P<$.05). Data representative of three separate experiments. a-SMA alpha-smooth muscle actin, ECM extracellular matrix, MDSC myeloid-derived suppressor cell

STZ mice using a OneTouch UltraEasy (Johnson-Johnson, New Brunswick, NJ, USA) monitor.

\section{Flow cytometric analysis}

Monoclonal antibodies (mAbs) against CD4, CD11b, CD25, CD40, CD80, CD86, F4/80, Gr-1, and I-Ab (MHC class II) were purchased from BD PharMingen (San Diego, CA, USA), and mAbs against B7-H1 and Foxp3 were purchased from eBioscience (San Diego, CA, USA). Intracellular staining protocols for regulatory $\mathrm{T}$ cells were followed for Foxp3 staining. For carboxyfluorescein succinimidyl ester (CFSE) labeling, splenic $\mathrm{T}$ cells $\left(10^{7} / \mathrm{ml}\right)$ from BALB/c mice were incubated with $0.5 \mu \mathrm{M}$ of CFSE (Invitrogen, San Diego, CA, USA) for $10 \mathrm{~min}$ at room temperature. Flow analyses were performed with a $\mathrm{BD}$ FACSCanto II flow cytometer (BD Bioscience, Franklin Lakes, NJ, USA).

\section{Cytokine antibody array assay}

A cytokine antibody array assay was performed with a mouse cytokine array kit (R\&D Systems) according to the manufacturer's protocol. Briefly, culture supernatants from MMCs were collected and centrifuged. After centrifugation, the assay membranes, which had been precoated with capture antibodies, were incubated with the supernatants. The membranes were then washed with wash buffer and a detection antibody was added using streptavidin-horseradish peroxidase (HRP) and Chemi Reagent Mix. The immunoblot images were captured and visualized using the BioSpectrum Imaging System (Ultra-Violet Products, Ltd, Cambridge, UK) and the intensity of each spot in the captured images was analyzed using ImageQuant 5.0 software (Molecular Dynamics).

\section{Quantitative reverse transcription PCR}

Total RNA was extracted with an RNeasy Mini Kit (Qiagen, Valencia, CA, USA). RNA samples were first converted into cDNA using a RevertAid First Strand cDNA Synthesis Kit (Thermo Fisher, Waltham, MA, USA). For quantitative PCR, the primers were: arginase 1, forward CACGG
CAGTG GCTTT AACCT and reverse TGGCG CATTC ACAGT CACTT; iNOS, forward TGGCC ACCTT GTTC AG CTACG and reverse GCCAA GGCCA AACAC AGCAT AC; fibronectin, forward GCTCA GCAAA TCGT G CAGC and reverse CTAGG TAGGT CCGTT CCCAC T; collagen type IV, forward AAAGG GAGAA AGAGG CTTGC and reverse CCTTT GTACC GTTGC ATCCT; and alpha-smooth muscle actin ( $\alpha$-SMA), forward ATGGC TCTGG GCTCT GTAAG and reverse TCTGG GACGT CCCAC GATGGA. mRNAs were measured using a CFX96 Touch Real Time PCR system (Bio-Rad Laboratories, Inc., Hercules, CA, USA) in duplicate and were normalized to $18 \mathrm{~S}$ mRNA.

\section{Immunofluorescence staining and confocal microscopy}

Tissue samples were embedded in optimal cutting temperature compound (OCT) and snap frozen in liquid nitrogen. Tissue sections $(4 \mu \mathrm{m})$ were fixed in ethanol/ acetic acid fixative solution for 2-10 min, and then were stained with anti-fibronectin (Abcam), CD11b (BD Biosciences), Gr-1 (BD Biosciences), DAPI (Invitrogen), and Alexa Fluor 488 Phalloidin (Invitrogen) overnight at $4{ }^{\circ} \mathrm{C}$ in a humidified chamber. After three washes, slides were stained with DAPI and mounted with ProLong Gold mounting medium (Invitrogen). Confocal imaging was performed using a Leica SP5 II confocal microscope.

\section{Immunohistochemistry}

Extracellular matrix expression of the renal cortex in cryostat sections was identified by fluorescent staining using a specific anti-fibronectin (Abcam), anti-collagen type IV (Abcam), anti-alpha-smooth muscle actin (Abcam), anti-Gr1 (BD Biosciences) antibody, following permeabilization with $0.05 \%$ saponin buffer using a Vectastain Elite ABC kit (Vector Lab, Inc., Burlingame, CA, USA) as immunoperoxidase. The slides were developed using AEC Chromogen/Substrate and counterstained with hematoxylin. Isotype and species-matched irrelevant antibodies served as controls. 


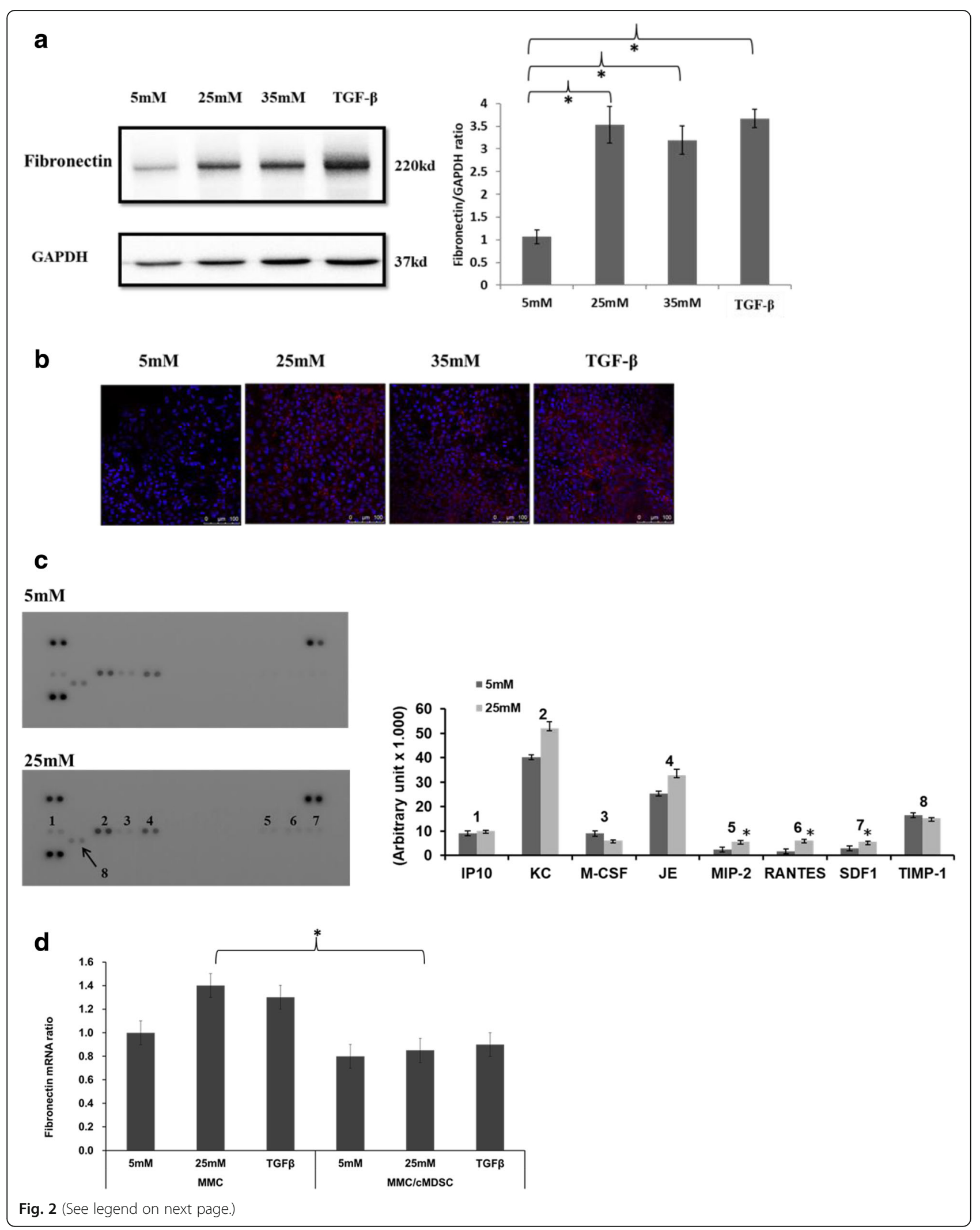




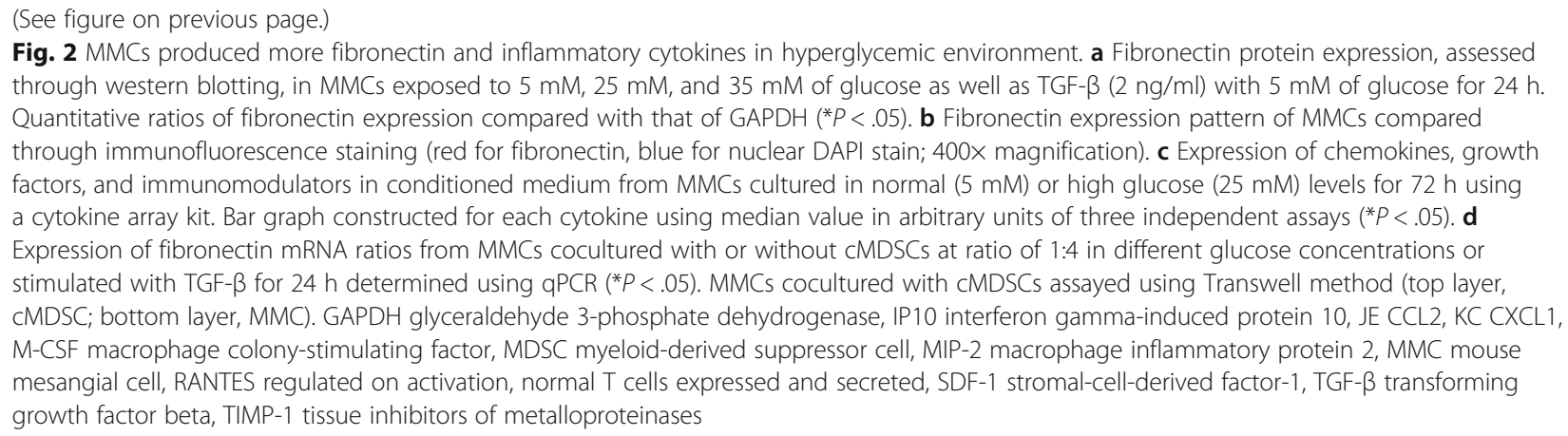

\section{Western blot analysis}

Protein extracts were separated by SDS-PAGE and transferred onto PVDF membranes before being probed with antibodies against fibronectin (15613-1-AP; Proteintech, Chicago, IL, USA) or GAPDH (sc-32,233; Santa Cruz Biotechnology, Santa Cruz, CA, USA). Proteins of interest were detected with an HRP-conjugated goat anti-mouse IgG antibody (sa00001-1; Proteintech) and visualized with a Pierce ECL Western blotting substrate (Thermo Scientific, Rockford, IL, USA) according to the provided protocol.

\section{Blood and urine analysis}

Blood glucose was determined using a OneTouch UltraEasy (Johnson-Johnson) monitor. Blood and urine were collected for examination of serum creatinine and protein when the mice were sacrificed, and serum creatinine and urinary protein were determined using a Labospect 008 (Hitachi, Tokyo, Japan).

\section{Statistical analyses}

Statistical analyses were performed using Student's $t$ test for independent samples, with significance determined at $P<.05$. All data, means, and standard deviations (SDs) were calculated and graphed in Microsoft Excel (Microsoft, Redmond, WA, USA).

\section{Results}

\section{High extracellular matrix expression of renal cortex and} MDSC redistribution in STZ-treated diabetic mice

Diabetes is a proinflammatory state. ECM accumulation in the renal parenchyma plays a pivotal role in the pathogenesis of diabetic nephropathy. In our study, ECMsuch as fibronectin, collagen type IV, and alpha-smooth muscle actin ( $\alpha$-SMA) - in the renal cortex was more highly expressed in the STZ-treated mice than in the untreated mice (Fig. 1a, $P<.05$ ). Fibronectin was primarily accumulated in the glomerulus, whereas collagen type IV and $\alpha$-SMA were largely gathered in the renal tubules. Serum creatinine $(0.83 \pm 0.18$ vs $0.27 \pm 0.05 \mathrm{mg} / \mathrm{dl})$ and urinary protein $(85.00 \pm 10.00$ vs $22.00 \pm 6.56 \mathrm{mg} / \mathrm{dl})$ levels were significantly higher in the STZ-treated mice than in the untreated mice (Fig. 1b, $P<.05$ ).

MDSCs are heterogeneous immature myeloid cells that rapidly expand to regulate host immunity during inflammation, infection, and cancer. The distribution of MDSCs within a hyperglycemic environment was investigated through in-vivo assays. As shown in Fig. 1c, the number of MDSCs in STZ-treated mice was lower in the $\mathrm{BM}(46.9 \%$ vs $63.2 \%, P=.16)$ than in the untreated mice, whereas the ratios of MDSCs increased in the peripheral blood (36.5\% vs $20.5 \%, P=.07)$, spleen $(6.8 \%$ vs $3.93 \%, P=.03)$, and kidneys $(0.304 \%$ vs $0.225 \%, P=.14)$. As an inflammatory state, diabetes may trigger the redistribution of MDSCs from the BM to peripheral organs, including the peripheral blood, spleen, and kidneys. Similar results of MDSC expansion were also noted in the spleen parenchyma (Fig. 1d, upper panel), and a slight increase was observed in the renal glomerulus (Fig. 1d, upper panel, dotted circle) in the STZ-treated mice through immunofluorescence staining. The numbers of MDSCs within the spleen parenchyma and renal glomerulus in the STZ-treated mice were 2.3 and 1.75 times that of untreated mice $(P<.05$ and $P=.183$, respectively; Fig. $1 d$, lower panel). Together, these results demonstrated that higher ECM expression occurs in the renal cortex, and that MDSCs are redistributed from the BM to the peripheral organs in STZ-treated diabetic mice.

\section{Hyperglycemic MMCs produce more fibronectin and proinflammatory cytokines}

Mesangial cells are specialized cells that accumulate in the glomerular mesangium and, together with mesangial matrix, form the vascular pole of the glomerulus. These cells play a crucial role in the process of glomerulosclerosis in diabetic nephropathy. As shown in Fig. 2a, fibronectin protein expression was found to be significantly higher in MMCs under hyperglycemic conditions and in MMCs stimulated with transforming growth factor beta (TGF- $\beta$ ) cytokine compared with MMCs under normal glucose 


\section{a}
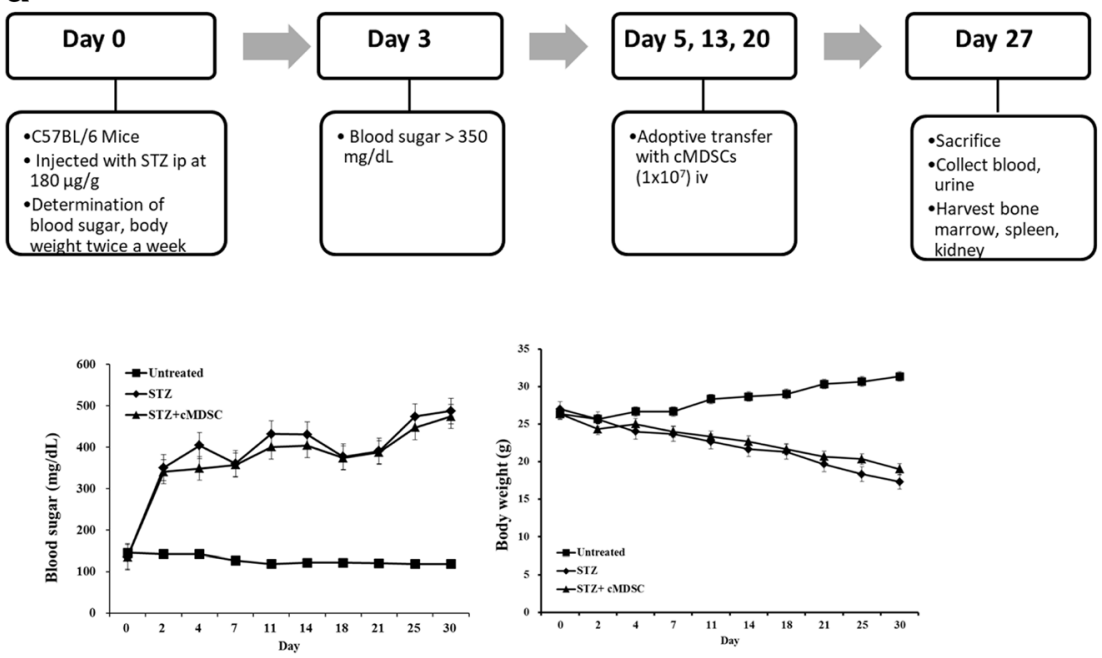

b
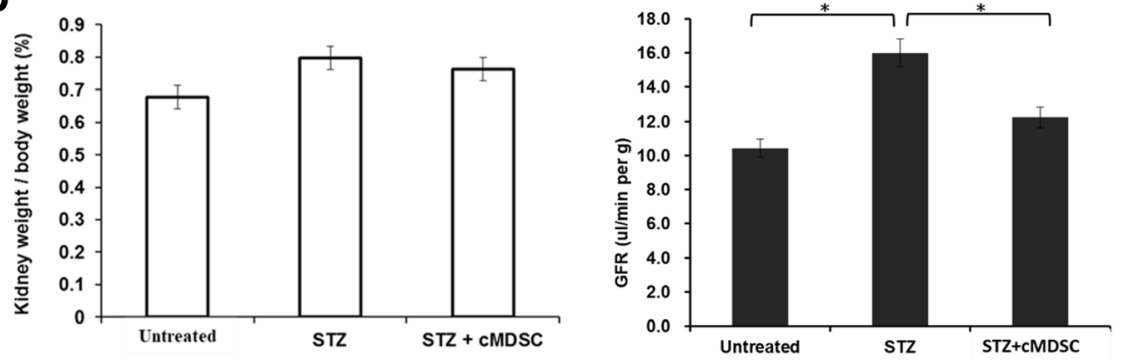

C

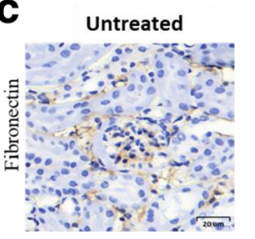

STZ

STZ+CMDSC
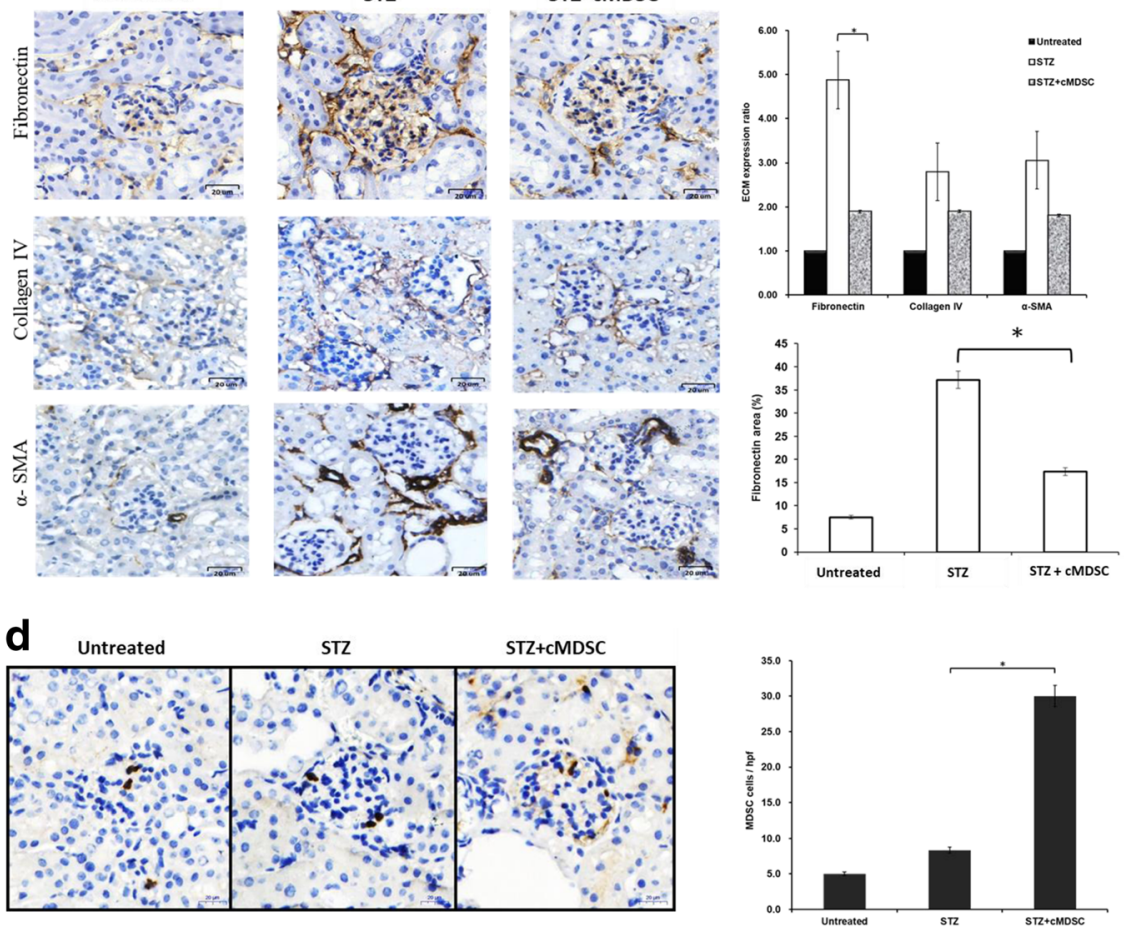

Fig. 3 (See legend on next page.) 
(See figure on previous page.)

Fig. 3 Adoptive transfer of CMDSCs into STZ-treated diabetic mice. a Cytokine-induced MDSCs $\left(1 \times 10^{7}\right.$ cells $)$ adoptively transferred into STZ mice through pudendal vein once a week (on days 5, 13, and 20). Mice in each group then sacrificed on day 27 (upper panel). Blood sugar levels and body weight (lower panel) measured twice a week until mice sacrificed in subgroups of untreated mice (untreated, $n=5$ ), STZ-treated diabetic mice (STZ, $n=5)$, and CMDSC-treated STZ mice (STZ + cMDSC, $n=5)$. b Kidneys harvested and weights measured on day 27. Ratios of kidney weight to body weight of the three groups compared (left panel). GFRs of the three groups examined and compared (right panel) $\left({ }^{*} P<.05\right)$. $\mathbf{c}$ Kidney cryostat sections histochemically stained with anti-fibronectin mAb, anti-collagen type IV mAb, or anti-alpha-smooth muscle actin mAb (left panel, brown; 400x magnification) and examined using a microscope. Bar graph presents quantification of ECM expression of renal cortex of untreated mice, STZ mice, and CMDSC-treated STZ mice (right upper panel) $\left.{ }^{*} P<.05\right)$. Areas of fibronectin expression within the glomeruli of the three groups quantified (right lower panel) ( $\left.{ }^{*} P<.05\right)$. d Presence of MDSCs in kidneys analyzed through histochemical staining with anti-Gr-1 mAb (left panel, brown; 400x magnification) and examined using a microscope. Bar graph illustrates positive MDSCs counted in a total of 10 high-power fields randomly selected in each section (right panel) $\left({ }^{*} P<.05\right)$. a-SMA alpha-smooth muscle actin, cMDSC cytokine-induced myeloid-derived suppressor cell, ECM extracellular matrix, GFR glomerular filtration rate, iv intravenous, STZ streptozotocin

concentrations (5 mM, $P<.05)$. Through immunofluorescence staining, a similar result was observed in MMCs that expressed higher levels of fibronectin when cultured under hyperglycemic conditions or when stimulated with TGF- $\beta$ cytokine (Fig. 2b).

To identify differences in cytokines released from MMCs between normal glucose $(5 \mathrm{mM})$ and high glucose $(25 \mathrm{mM})$ levels, a cytokine array assay was conducted. Multiple cytokines were detected in MMC medium incubated with $5 \mathrm{mM}$ or $25 \mathrm{mM}$ of glucose. Cytokines IP10, KC, JE, MIP-2, RANTES, and SDF-1 tended to exhibit higher expression levels in the 25-mM group. Among those identified, MIP-2, RANTES, and SDF-1 levels were significantly higher in the $25-\mathrm{mM}$ group (Fig. 2c, $P<.05$ ) than in normal glucose conditions.

According to the aforementioned results, MMCs produced more fibronectin and proinflammatory cytokines under hyperglycemic conditions than did MMCs under standard conditions. MDSCs have been reported to participate in immune suppression and autoimmune disorders. Specifically, the adoptive transfer of MDSCs prevented autoimmune arthritis in mouse models [18]. To examine the influence of MDSCs on MMCs in a hyperglycemic environment, cytokine-induced MDSCs were propagated and cocultured with MMCs using a Transwell assay. As illustrated in Fig. 2d, MMCs decreased the production of fibronectin mRNA in the presence of cMDSCs, especially when the mice were in a hyperglycemic state $(25 \mathrm{mM}, P=.04)$. These results suggest that MMCs produce elevated levels of fibronectin and proinflammatory cytokines under hyperglycemic conditions and that cMDSCs attenuate fibronectin production in vitro.

\section{cMDSCs ameliorate renal fibronectin expression in STZ-treated diabetic mice}

To examine whether the anti-inflammatory effect of MDSCs influenced the production of renal fibronectin in diabetic mice, cMDSCs were adoptively transferred into STZ-treated mice (Fig. 3a, upper panel). As presented in Fig. 3a, blood sugar levels were higher in the cMDSC-treated and untreated STZ mice than in the untreated control mice (Fig. 3a, lower left panel). Similarly, body weight was reduced in both STZ groups in comparison with the untreated group (Fig. 3a, lower right panel). The adoptive transfer of cMDSCs did not change the blood sugar and body weight of diabetic mice. However, the kidney weight in proportion to body weight was higher in STZ mice compared with untreated mice, but treatment with cMDSCs reduced the magnitude of these differences (Fig. 3b, left panel, $P>.05$ ). The glomerular filtration rate (GFR) is the optimal test for measuring kidney function and determining the kidney disease stage. The level of GFR was elevated in STZ mice compared with untreated mice $(16.00 \pm 2.00$ vs $10.43 \pm 1.40 \mu \mathrm{l} / \mathrm{min} / \mathrm{g}, \quad P=.004)$, whereas this level was reduced after the administration of cMDSCs into STZ mice $(16.00 \pm 2.00$ vs $12.23 \pm 1.12 \mu \mathrm{l} / \mathrm{min} / \mathrm{g}$, $P=.020)$ (Fig. 3b, right panel).

Glomerulosclerosis in patients with diabetic nephropathy is caused by the accumulation of ECM proteins in the mesangial interstitial space. Fibronectin is a crucial component of ECM proteins. In our study, fibronectin production in the renal glomerulus was significantly increased in STZ mice, but the administration of cMDSCs ameliorated this abnormal fibronectin and reduced the resulting glomerular area accumulation in STZ mice (Fig. 3c, $P<.05$ ). In the other two groups, ECM, collagen type IV, and $\alpha$-SMA decreased the production of fibronectin after treatment with cMDSCs, but no statistical difference was observed $(P>.05)$. The number of MDSCs within the glomerulus was considerably enhanced in the STZ mice receiving cMDSC treatment (Fig. 3d). Taken together, these data indicate that cMDSCs exhibit anti-inflammatory properties that substantially improve fibronectin accumulation in the renal glomerulus and normalize the GFR in STZ-treated diabetic mice. 

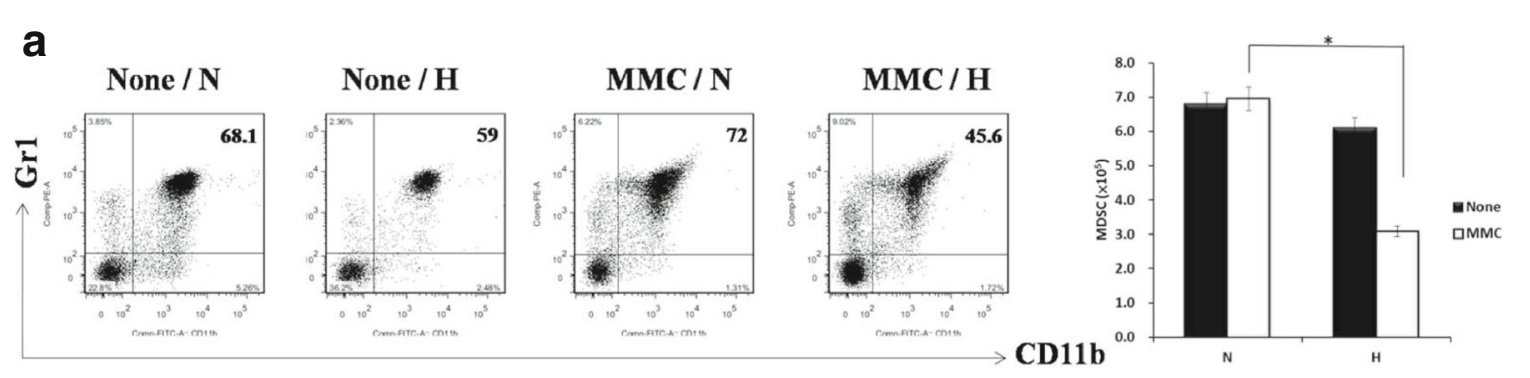

b
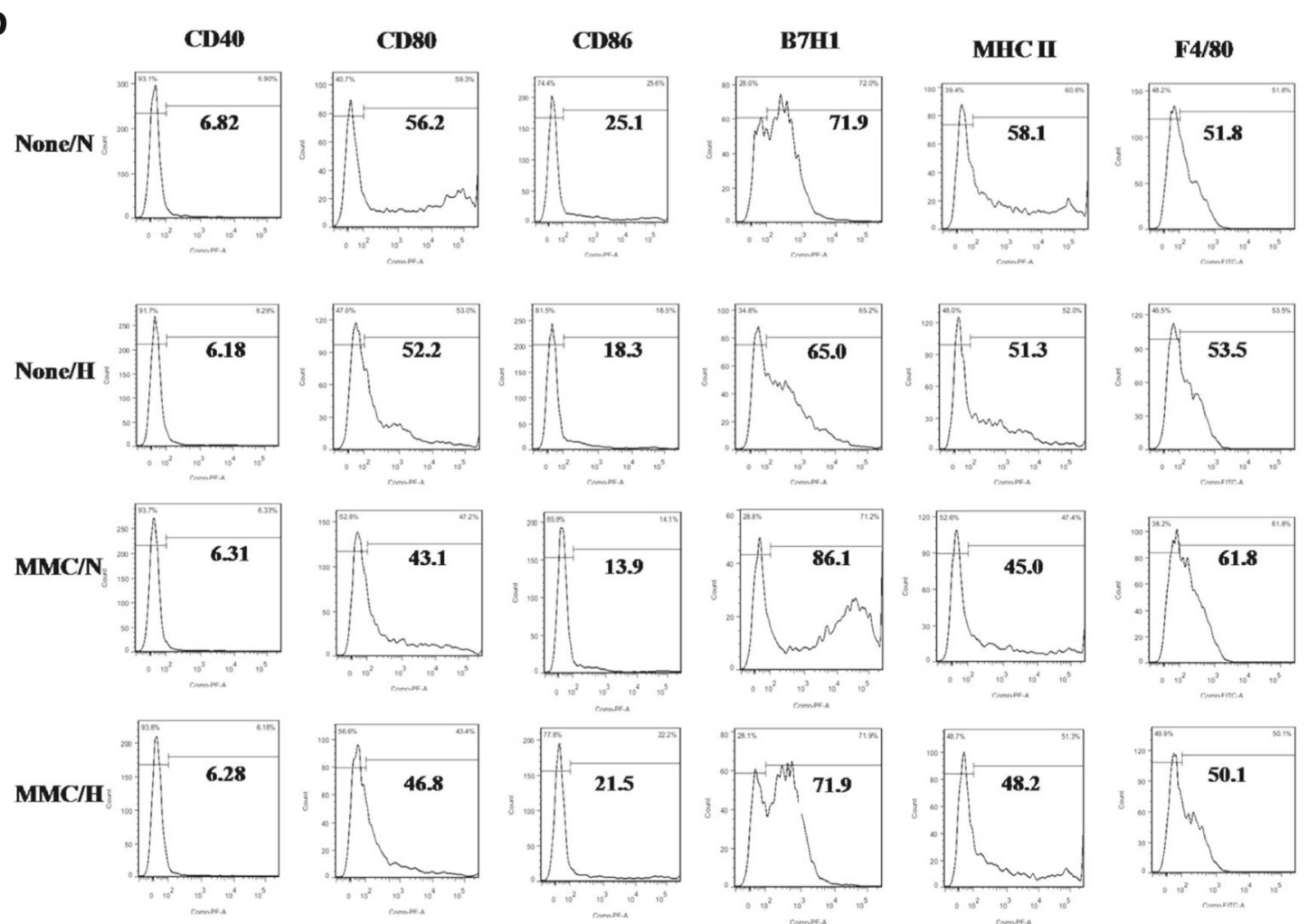

C
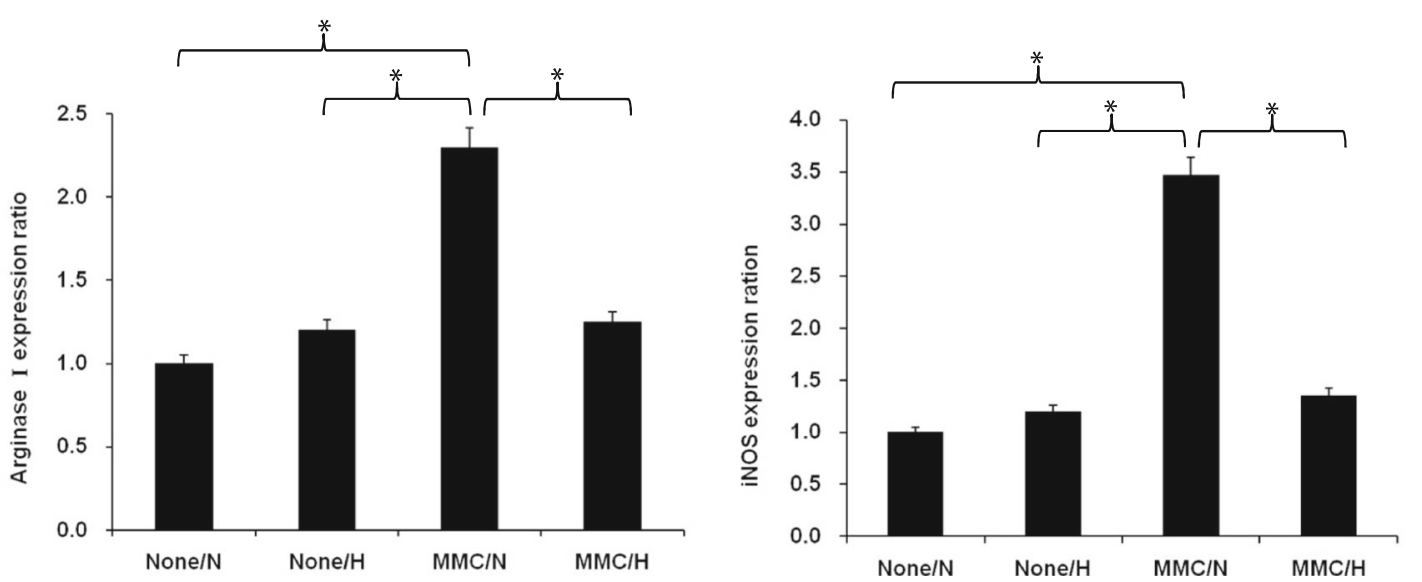

Fig. 4 (See legend on next page.) 
(See figure on previous page.)

Fig. 4 Effects of MMCs on development of MDSCs under hyperglycemic conditions. BM cells from femur and tibia of B6 mice mixed with or without MMCs in presence of mouse recombinant GM-CSF $(10 \mathrm{ng} / \mathrm{ml})$ at ratio of 80:1 under normal (N) $(5 \mathrm{mM}, 90 \mathrm{mg} / \mathrm{dl})$ or high (H) $(25 \mathrm{mM}$, $450 \mathrm{mg} / \mathrm{dl}$ ) glucose conditions. Cells isolated for examination 7 days later. a Isolated cells two-color stained with specific mAbs against CD11b and $\mathrm{Gr}-1$ for flow analyses. Four groups divided based on presence or absence of MMCs and glucose levels. Production of MDSCs from different cultured systems measured. Double-positive CD11b and Gr-1 cells represent MDSCs. Bar graph displays yield of MDSCs for each group. Data expressed as mean $C D 11 b^{+} / G r-1^{+}$cells \pm 1 SD $\left({ }^{*} P<.05\right)$. b Cell surface molecules stained with specific mAbs against CD40, CD80, CD86, B7H1, MHC class II, and F4/80. Numbers represent percentage of positive cells. $\mathbf{c}$ Expression of arginase 1 and iNOS mRNA from MDSCs determined using $\mathrm{qPCR}\left({ }^{*} P<.05\right)$. Data representative of three separate experiments. iNOS inducible nitric oxide synthase, MDSC myeloid-derived suppressor cell, MMC mouse mesangial cell

\section{MMCs reduce MDSC production and function under hyperglycemic conditions in vitro}

The influence of components from the blood, especially circulating immune cells, on mesangial cells may contribute to the pathogenesis of glomerulosclerosis. To examine the interaction between mesangial and immune cells we set up an in-vitro culture system to generate MDSCs $\left(\mathrm{CD}_{11} \mathrm{~b}^{+} / \mathrm{Gr}^{+}\right)$through coculturing MMCs with BM-derived monocytes under normal $(5 \mathrm{mM})$ or high $(25 \mathrm{mM})$ glucose levels.

Compared with normal glucose levels, MDSC production was slightly decreased in a high-glucose environment and slightly increased when cocultured with MMCs at a normal glucose level (Fig. 4a, left panel). By contrast, the production of MDSCs was substantially reduced when cocultured with MMCs under hyperglycemic conditions (Fig. 4a, right panel). This result demonstrated that MMCs probably attenuate MDSC development under hyperglycemic conditions. The effect of D-mannitol didn't influence MDSCs production (Additional file 2: Figure S2). MDSCs expressed less costimulatory CD80, CD86, and MHC class II and more inhibitory B7H1 under the influence of MMCs in the normal glucose environment (Fig. 4b), indicating that MMC-directed MDSCs exhibit a greater capacity to suppress the immune response than do MDSCs alone. By contrast, MMC-directed MDSCs weaken the immunomodulatory ability of these cells in a hyperglycemic environment.

Arginase I and inducible NO synthase (iNOS) are known to participate in the immunoregulatory activities of MDSCs. In our study, MMC-directed MDSCs in normal glucose conditions expressed the highest levels of arginase 1and iNOS among the four cultured groups (Fig. $4 \mathrm{c}, P<.05$ ). In high-glucose conditions, MDSCs mediated by MMCs exhibited significantly reduced immunosuppressive properties compared with those of MMC-directed MDSCs in normal glucose conditions. Taken together, these results suggest that MMCs diminished the production of MDSCs and their immunosuppressive function in a hyperglycemic environment.

\section{Hyperglycemic MMC-directed MDSCs modulate adaptive immunity and induce an inflammatory state}

Members of the MDSC-expressed MHC class II (Fig. 4b) proteins are normally found only on antigen-presenting cells that initiate adaptive immune responses. To verify the functions of MDSCs and the influence of adaptive immunity, especially in T cells, an alloreactive T-cell proliferation and differentiation assay as well as a cytokine production assay were performed. MMC-conditioned MDSCs induced more allogeneic T-cell activation in a hyperglycemic state than at normal glucose levels (Fig. 5a, upper panel). The total T-cell counts after the introduction of MMC-conditioned MDSCs were considerably higher in the mice subjected to the hyperglycemic environment than those in the normal glucose conditions (Fig. 5a, lower panel, $P<.05$ ).

Regulatory $\mathrm{T}$ cells $\left(\mathrm{CD} 4^{+} / \mathrm{CD} 25^{+} / \mathrm{FoxP}^{+}\right)$are a subpopulation of T cells that modulate the immune system, maintain tolerance to self-antigens, and prevent autoimmune disease. The induction of regulatory $\mathrm{T}$ cells is a possible mechanism by which MDSCs suppress the host's proinflammatory immunity. In our study, MMC-directed MDSCs elicited greater regulatory T-cell differentiation in normal glucose levels than in hyperglycemic conditions (Fig. 5b, $P<.05$ ). More interferon gamma (IFN $\gamma$ ), a proinflammatory cytokine, was secreted from $\mathrm{T}$ cells stimulated by MMC-conditioned MDSCs under the hyperglycemic conditions than MDSCs in the normal glucose environment (Fig. 5c, $P<.05$ ). These data reveal that MDSCs conditioned by MMCs in a hyperglycemic state had a reduced inhibitory immune response, and an inflammatory environment was created. A model for the interaction between renal stromal cells and MDSCs during chronic inflammation under diabetic conditions is proposed in Fig. 5d.

\section{Discussion}

Diabetic nephropathy is currently the most common cause of end-stage renal disease worldwide [2]. Glomerulosclerosis is a key contributor to diabetic nephropathy. Glomerulosclerosis is caused by accumulation of ECM proteins in the mesangial interstitial space, resulting in fibrosis [3]. Mesangial cells are unique stromal cells that account for approximately $30-40 \%$ of the total cells in the renal glomerulus [19] and form the vascular pole of the renal corpuscle with the mesangial matrix [20]. The influence of the circulating immune cells on mesangial 


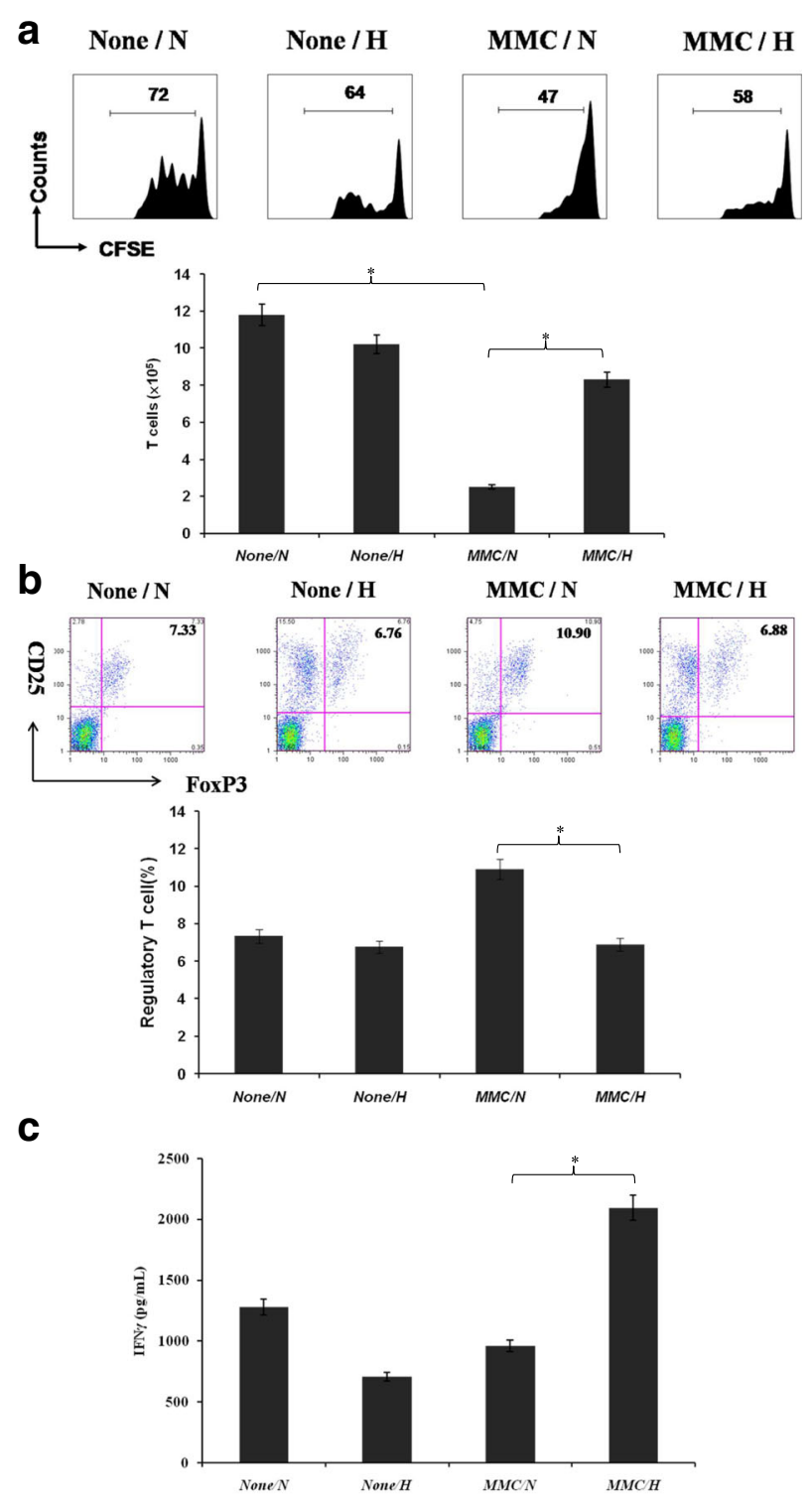

d

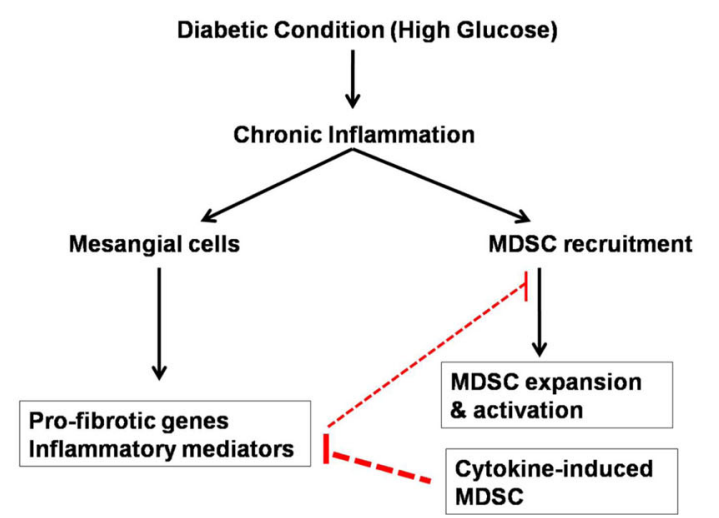

Fig. 5 (See legend on next page.) 


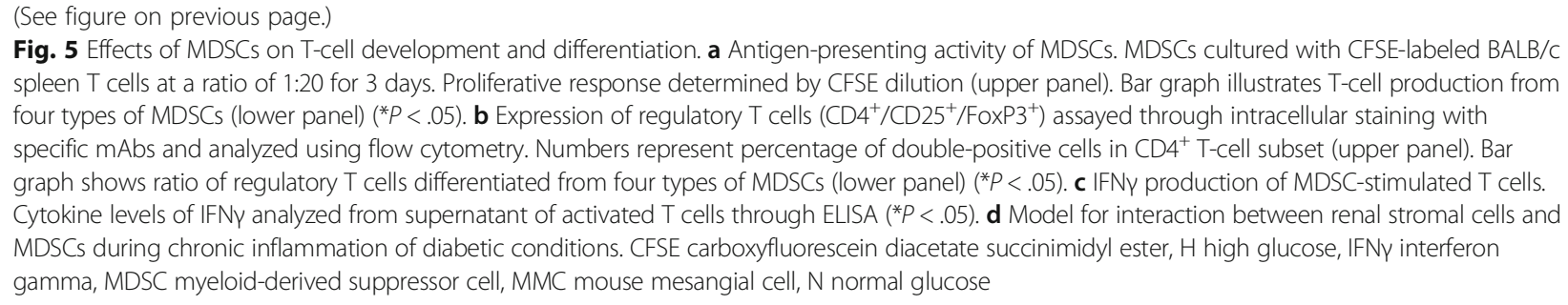

cells may contribute to the pathogenesis of glomerulosclerosis in diabetic nephropathy.

Understanding the population dynamics of MDSCs during diabetes progression is a crucial step in elucidating the possible role of MDSCs in diabetic nephropathy. In this study, STZ-treated mice had an increased proportion of MDSCs in the peripheral blood, spleen, and kidneys, whereas a decrease was noted in the relative number of MDSCs in the BM. This was likely caused by the inflammatory diabetic state, which could have triggered immature myeloid cells to be redistributed from the $\mathrm{BM}$ into peripheral organs. The ratio of MDSCs (63.2\%) within BM cells in healthy mice here was higher than that was approximately $30 \%$ of BM cells in other study [21]. The possible reasons are the heterogeneity of MDSCs, including immature granulocytes, macrophages, and dendritic cells, and the sensitivity of monoclonal antibodies to CD11b and $\mathrm{Gr}-1$. The function of splenic MDSCs isolated from STZ-treated mice was less inhibitory to T-cell proliferation than those isolated from untreated mice (Additional file 3: Figure S3). Whitfield-Larry et al. [22] reported an increase in MDSCs in the peripheral blood and spleen, and a reduction of such cells in the pancreatic islets of nonobese diabetic (NOD) mice. The functions of native MDSCs in NOD mice are not as maximally suppressive of T-cell proliferation compared with those in in-vitro conditions induced by IL- $1 \beta$ and GM-CSF cytokines. MDSCs are redistributed from the BM into peripheral organs and have a reduced suppressive activity in diabetic mice.

MMCs produced more fibronectin and proinflammatory cytokines, such as MIP-2, RANTES, and SDF-1, under hyperglycemic conditions. Fibronectin has a crucial role in the organization of ECM components and the pathogenesis of glomerulosclerosis in diabetic nephropathy [23]. The TGF- $\beta /$ mothers against decapentaplegic homolog (SMAD) axis is arguably the most critical signaling pathway involved in fibronectin production in mesangial cells [24]. MIP-2 is a chemokine and chemoattractant for polymorphonuclear leukocytes that is involved in inflammatory processes [25]. The chemokine of RANTES (CCL5) is chemotactic for $\mathrm{T}$ cells, eosinophils, and basophils, and plays an active role in recruiting leukocytes into inflammatory sites, as well as promoting cancer progression [26]. SDF-1 is also chemotactic for mesenchymal stem cell migration in response to inflammatory stimuli [27]. Collectively, both the major components of ECM and proinflammatory cytokines secreted from renal stromal cells under hyperglycemic conditions enhance fibrotic changes in the glomerulus.

MDSCs are heterogeneous immature myeloid cells that rapidly expand to regulate host immunity during inflammation, infection, and cancer. Immunoregulatory activities within MDSCs include increased production of arginase I, inducible NO synthase, reactive oxygen species, and anti-inflammatory cytokines [28]. Investigating the interaction between renal stromal cells and circulating immune cells, such as MDSCs, is a critical step in elucidating the mechanisms of glomerulosclerosis in diabetic nephropathy. In this study, we assembled an in-vitro culture system to generate MDSCs $\left(\mathrm{CD}_{11} \mathrm{~b}^{+} / \mathrm{Gr}^{+}\right)$by coculturing MMCs with BM-derived monocytes. The production of MDSCs was significantly reduced when BM cells were cocultured with MMCs under hyperglycemic conditions $(25 \mathrm{mM})$ compared with a normal glucose environment $(5 \mathrm{mM})$. The results demonstrated that mesangial cells attenuated MDSC development in a hyperglycemic environment.

MDSCs expressed more costimulatory CD86 and less inhibitory B7H1 as well as lower arginase I and iNOS levels under the influence of MMCs in a high-glucose environment compared with those propagated with MMCs in normal glucose conditions. MDSCs are antigen-presenting cells that initiate adaptive immunity. In the present study, hyperglycemic MMC-directed MDSCs induced more allogeneic T cells, less regulatory T cells, and higher IFN $\gamma$ levels than did normoglycemic MMC-induced MDSCs. Taken together, MDSCs conditioned by MMCs in a hyperglycemic state exhibited diminished inhibitory immune activities and created an inflammatory environment in the in-vitro cocultured assay.

Immunotherapy provides an alternative treatment protocol for patients with cancer or inflammation $[29,30]$ and those requiring organ transplantation [31, 32]. MDSCs have been extensively used for immunotherapy based on their immunosuppressive and anti-inflammatory activities. The most widely used sources of MDSCs originate from tumor-bearing mice [16] and ex-vivo procedures with GM-CSF-based cytokines [17, 33]. Differentiating MDSCs using ex-vivo procedures is a feasible and safe method 
compared with MDSCs propagated from tumor-bearing mice. In this study, cytokine-induced MDSCs were obtained from BM cells cultured with GM-CSF, IL-1 $\beta$, and IL-6 cytokines. The purity of the cytokine-induced MDSCs was more than $90 \%$ in the presence of GM-CSF, IL-1 $\beta$, and IL-6 cytokines (Additional file 1: Figure S1). The immunoregulatory functions of MDSCs induced by a combination of GM-CSF, IL-1 $\beta$, and IL- 6 have more intense activities than those induced by GM-CSF and IL-1 $\beta$ [22] or GM-CSF and IL-6 [33] (Additional file 4: Figure S4). The increased ratio of kidney to body weight and GFR in STZ-treated diabetic mice indicated that hyperfiltration in early onset diabetes causes hypertrophy. The kidney to body weight ratio and the GFR were normalized after treatment with cytokine-induced MDSCs. In addition, the adoptive transfer of cytokine-induced MDSCs into STZ-treated mice reduced fibronectin accumulation in the renal glomerulus, ameliorating renal glomerulosclerosis. These results demonstrate that the anti-inflammatory activities of cytokine-induced MDSCs offer an alternative immunotherapy protocol for patients with diabetic nephropathy.

\section{Conclusion}

The application of cytokine-induced MDSCs provides a promising strategy for the treatment of glomerulosclerosis and the prevention of diabetic nephropathy.

\section{Additional files}

Additional file 1: Figure S1. Propagation of cytokine-induced MDSCS. Cytokine-induced MDSCs were propagated from BM cells cultured with mouse recombinant GM-CSF alone, GM-CSF + IL-6, GM-CSF + IL-1 $\beta$, or GM-CSF + IL- $6+$ IL-1 $\beta$ for 7 days. Isolated cells two-color stained with specific mAbs against CD11b and Gr-1 for flow analyses. Four groups divided based on different cytokine-cultured conditions. $C D 11 b^{+}$and $\mathrm{Gr}-1^{+}$cells represent MDSCs (PDF $141 \mathrm{~kb}$ )

Additional file 2: Figure S4. Glucose, not D-mannitol, reduced MDSC production. BM cells from femur and tibia of B6 mice were cultured in presence of mouse recombinant GM-CSF $(10 \mathrm{ng} / \mathrm{ml})$ under normal or high glucose conditions with or without $20 \mathrm{mM}$ of D-mannitol. Cells isolated for examination 7 days later. Isolated cells two-color stained with specific mAbs against CD11b and Gr-1 for flow analyses (PDF $111 \mathrm{~kb}$ )

Additional file 3: Figure S2. MDSCs isolated from STZ-treated mice inhibit less T-cell proliferative responses. CFSE-labeled B6 mice spleen T cells were cultured with splenic MDSCs isolated from STZ-treated mice or untreated mice at ratio of 10:1, 20:1, or $40: 1$ in presence of $1 \mu \mathrm{g} / \mathrm{ml}$ of CD3/CD28 for 3 days. Proliferation of T cells determined by CFSE dilution (PDF $120 \mathrm{~kb}$ )

Additional file 4: Figure S3. mRNA expression of arginase 1 and iNOS in cytokine-induced MDSCs. Expression of arginase 1 and iNOS mRNA from MDSCs derived from BM cells propagated for 7 days in presence of GM-CSF alone, GM-CSF + IL-1 $\beta$, GM-CSF + IL6, and GM-CSF+ IL-1 $\beta+$ IL6 determined through $\mathrm{GPCR}\left({ }^{*} P<.05\right)$. Data representative of three separate experiments (PDF $53 \mathrm{~kb}$ )

\section{Abbreviations}

B7H1: B7 homolog 1; BM: Bone marrow; CD: Cluster of differentiation; CFSE: Carboxyfluorescein succinimidyl ester; cMDSC: Cytokine-induced myeloid-derived suppressor cell; ECM: Extracellular matrix GAPDH: Glyceraldehyde 3-phosphate dehydrogenase; GFR: Glomerular filtration rate; GM-CSF: Granulocyte-macrophage colony-stimulating factor; IFNY: Interferon gamma; L-1ß: Interleukin 1 beta; IL-6: Interleukin 6; iNOS: Inducible NO synthase; IP10: Interferon gamma-induced protein 10; JE: CCL2; KC: CXCL1; MDSC: Myeloid-derived suppressor cell; MHC: Major histocompatibility complex; MIP-2: Macrophage inflammatory protein-2; MMC: Mouse mesangial cell; NOD: Nonobese diabetic; OCT: Optimal cutting temperature; PCR: Polymerase chain reaction; RANTES: Regulated on activation, normal T cells expressed and secreted; SDF-1: Stromal-cell-derived factor-1; STZ: Streptozotocin; TGF- $\beta$ : Transforming growth factor beta; aSMA: alpha-smooth muscle actin

\section{Acknowledgements}

The authors would like to thank the Expensive Advanced Instrument Core Laboratory in the Department of Medical Research and Development of Chang Gung Memorial Hospital at Chiayi for offering the use of their BD FACSCanto II flow cytometer, BD FACSAria Fusion cell sorter, and Leica SF5 || confocal microscope.

\section{Funding}

The work was supported by the Ministry of Science and Technology (Taiwan) under grant 106-2314-B-182A-104-MY2 and by Chang Gung Memorial Hospital under grant CMRPG6C0133 (both to C-CH).

\section{Availability of data and materials}

The authors declare that the datasets supporting the results of this study are included within the article and Additional files.

\section{Authors' contributions}

$\mathrm{C}-\mathrm{CH}$ conceived and designed the experiments, performed the experiments, analyzed the data, and wrote the paper. C-LL contributed reagents, analyzed the data, and wrote the paper. J-TH, MC, $\mathrm{WW}$, and Y-CT performed the experiments and analyzed the data. C-HH and P-JC contributed reagents/materials/analysis tools and conceived and designed the experiments. All authors read and approved the final manuscript.

\section{Ethics approval}

All animal experiments were approved by the Institutional Animal Care and Use Committee of the Chang Gung Memorial Hospital (IACUC permit number: 2012091902), and were performed in accordance with the Animal Protection Law by the Council of Agriculture, Executive Yuan (Taiwan) and the National Research Council's Guide for the Care and Use of Laboratory Animals (USA).

\section{Competing interests}

The authors declare that they have no competing interests.

\section{Publisher's Note}

Springer Nature remains neutral with regard to jurisdictional claims in published maps and institutional affiliations.

\section{Author details}

'Graduate Institute of Clinical Medical Sciences, College of Medicine, Chang-Gung University, Taoyuan, Taiwan. ${ }^{2}$ Department of Surgery, Chang-Gung Memorial Hospital, 6, Sec. West Chia-Pu Road, Pu-Zi City, Chiayi County 613, Taiwan. ${ }^{3}$ Department of Nephrology, Chang-Gung Memorial Hospital, Chiayi, Taiwan. ${ }^{4}$ Kidney and Diabetic Complications Research Team (KDCRT), Chang-Gung Memorial Hospital, Chiayi, Taiwan.

Received: 6 February 2018 Revised: 17 May 2018

Accepted: 27 May 2018 Published online: 04 July 2018

\section{References}

1. Atkinson MA, Maclaren NK. The pathogenesis of insulin-dependent diabetes mellitus. N Engl J Med. 1994;331:1428-36. https://doi.org/10.1056/ nejm199411243312107.

2. Schieppati A, Remuzzi G. Chronic renal disease as a public health problem: epidemiology, social, and economic implications. Kidney Int. 2005;98 Suppl: S7-10. (PMID: 16108976. https://doi.org/10.1111/j.1523-1755.2005.09801.x.

3. Alsaad KO, Herzenberg AM. Distinguishing diabetic nephropathy from other causes of glomerulosclerosis: an update. J Clin Pathol. 2007:60:18-26. [PMID: 17213346; PMCID: PMC1860608. https://doi.org/10.1136/jcp.2005.035592. 
4. Zheng F, Cornacchia F, Schulman I, Banerjee A, Cheng QL, Potier M, Plati AR, Berho M, Elliot SJ, Li J, Fornoni A, Zang YJ, Zisman A, Striker LJ, Striker GE. Development of albuminuria and glomerular lesions in normoglycemic normoglycemic B6 recipients of $\mathrm{db} / \mathrm{db}$ mice bone marrow: the role of mesangial cell progenitors. Diabetes. 2004;53:2420-7. PMID: 15331554

5. You H, Gao T, Cooper TK, Brian Reeves W, Awad AS. Macrophages directly mediate diabetic renal injury. Am J Physiol Renal Physiol. 2013; 305(12):1719-27. [PMID: 24173355; PMCID: PMC3882451. https://doi.org/ 10.1152/ajprenal.00141.2013.

6. Young MR, Newby M, Wepsic TH. Hematopoiesis and suppressor bone marrow cells in mice bearing large metastatic Lewis lung carcinoma tumors. Cancer Res. 1987;47:100-6. PMID: 2947676.

7. Buessow SC, Paul RD, Lopez DM. Influence of mammary tumor progression on phenotype and function of spleen and in situ lymphocytes in mice. J Natl Cancer Inst. 1984;73:249-55. PMID: 6610791.

8. Seung L, Rowley D, Dubeym P, Schreiber H. Synergy between T-cell immunity and inhibition of paracrine stimulation causes tumor rejection. Proc Natl Acad Sci U S A. 1995;92:6254-8. PMID: 7603979; PMCID: PMC41496.

9. Gabrilovich DI, Nagaraj S. Myeloid-derived suppressor cells as regulators of the immune system. Nat Rev Immunol. 2009;9(3):162-74. [PMID: 19197294; PMCID: PMC2828349. https://doi.org/10.1038/nri2506.

10. Kusmartsev S, Nefedova Y, Yoder D, Gabrilovich DI. Antigen-specific inhibition of CD8+ T cell response by immature myeloid cells in cancer is mediated by reactive oxygen species. J Immunol. 2004;172: 989-99. PMID: 14707072.

11. Rodriguez PC, Hernandez CP, Quiceno D, Dubinett SM, Zabaleta J, Ochoa JB, Gilbert J, Ochoa AC. Arginase I in myeloid suppressor cells is induced by COX-2 in lung carcinoma. J Exp Med. 2005;202:931-9. [PMID: 16186186; PMCID: PMC2213169. https://doi.org/10.1084/jem.20050715.

12. Rodriguez PC, Ochoa AC. Arginine regulation by myeloid derived suppressor cells and tolerance in cancer: mechanisms and therapeutic perspectives. Immunol Rev. 2008;222:180-91. [PMID: 18364002; PMCID: PMC3546504. https://doi.org/10.1111/j.1600-065X.2008.00608.x.

13. Kusmartsev S, Nagaraj S, Gabrilovich DI. Tumor-associated CD8+ T cell tolerance induced by bone marrow-derived immature myeloid cells. J Immunol. 2005;175:4583-92. PMID: 16177103; PMCID: PMC1350970

14. Agostinelli E, Seiler N. Non-irradiation-derived reactive oxygen species (ROS) and cancer: therapeutic implications. Amino Acids. 2006;31:341-55. [PMID: 16680401. https://doi.org/10.1007/s00726-005-0271-8.

15. Huang B, Pan PY, Li Q, Sato Al, Levy DE, Bromberg J, Divino CM, Chen SH. Gr-1+CD115+ immature myeloid suppressor cells mediate the development of tumorinduced $T$ regulatory cells and T-cell anergy in tumor-bearing host. Cancer Res. 2006;66:1123-31. [PMID: 16424049. https://doi.org/10.1158/0008-5472.CAN-05-1299.

16. Corzo CA, Condamine T, Lu L, Cotter MJ, Youn Jl, Cheng P, Cho HI, Celis E, Quiceno DG, Padhya T, McCaffrey TV, McCaffrey JC, Gabrilovich DI. HIF1 alpha regulates function and differentiation of myeloid-derived suppressor cells in the tumor microenvironment. J Exp Med. 2010;207:2439-53. [PMID: 20876310; PMCID: PMC2964584. https://doi.org/10.1084/jem.20100587.

17. Lutz MB, Kukutsch NA, Menges M, Rössner S, Schuler G. Culture of bone marrow cells in GM-CSF plus high doses of lipopolysaccharide generates exclusively immature dendritic cells which induce alloantigen-specific CD4 T cell anergy in vitro. Eur J Immunol. 2000;30: 1048-52. PMID: 10760792; DOI: 10.1002/(SICI)1521-4141(200004)30:4\&\#60; 1048::AID-IMMU1048\&\#62;3.0.CO;2-W.

18. Zhang L, Zhang Z, Zhang H, Wu M, Wang Y. Myeloid-derived suppressor cells protect mouse models from autoimmune arthritis via controlling inflammatory response. Inflammation 2014;37(3):670-677. [PMID: 24264477; DOI: https://doi.org/10.1007/s10753-013-9783-z].

19. Olivetti G, Anversa P, Rigamonti W, Vitali-Mazza L, Loud AV. Morphometry of the renal corpuscle during normal postnatal growth and compensatory hypertrophy. A light microscope study. J Cell Biol. 1977;75:573-85. PMID: 264124; PMCID: PMC2109942.

20. Schlondorff D, Banas B. The Mesangial cell revisited: no cell is an island. J Am Soc Nephrol. 2009;20(6):1179-87. [PMID: 19470685. https://doi.org/10. 1681/ASN.2008050549.

21. E R, Greifenberg V, Sandwick S, Lutz MB. Subsets, expansion and activation of myeloid-derived suppressor cells. Med Microbiol Immunol. 2010;199(3): 273-81. [PMID: 20376485. https://doi.org/10.1007/s00430-010-0151-4.
22. Whitfield-Larry F, Felton J, Buse J, Su MA. Myeloid-derived suppressor cells are increased in frequency but not maximally suppressive in peripheral blood of type 1 diabetes mellitus patients. Clin Immunol. 2014;153(1):15664. [PMID: 24769355. https://doi.org/10.1016/j.clim.2014.04.006.

23. Mason RM, Wahab NA. Extracellular matrix metabolism in diabetic nephropathy. J Am Soc Nephrol. 2003;14(5):1358-73. PMID: 12707406

24. Haneda M, Koya D, Isono M, Kikkawa R. Overview of glucose signaling in mesangial cells in diabetic nephropathy. J Am Soc Nephrol. 2003; 14(5):1374-82. PMID: 12707407.

25. Rouault C, Pellegrinelli V, Schilch R, Cotillard A, Poitou C, Tordjman J, Sell H, Clément K, Lacasa D. Roles of chemokine ligand-2 (CXCL2) and neutrophils in influencing endothelial cell function and inflammation of human adipose tissue. Endocrinology. 2013;154(3):1069-79. [PMID: 23372021. https://doi.org/10.1210/en.2012-1415.

26. Aldinucci D, Colombatti A. The inflammatory chemokine CCL5 and cancer progression. Mediat Inflamm. 2014;2014:292376. [PMID: 24523569; PMCID: PMC3910068. https://doi.org/10.1155/2014/292376.

27. Yu Y, Wu RX, Gao LN, Xia Y, Tang HN, Chen FM. Stromal cell-derived factor-1-directed bone marrow mesenchymal stem cell migration in response to inflammatory and/or hypoxic stimuli. Cell Adhes Migr. 2016 10(4):342-59. [PMID: 26745021; PMCID: PMC4986706. https://doi.org/10. 1080/19336918.2016.1139287.

28. Gabrilovich DI. Myeloid-derived suppressor cells. Cancer Immunol Res. 2017; 5(1):3-8. [PMID: 28052991; PMCID: PMC5426480. https://doi.org/10.1158/ 2326-6066.CIR-16-0297.

29. Li Y, Tu Z, Qian S, Fung JJ, Markowitz SD, Kusner LL, Kaminski HJ, Lu L, Lin F. Myeloid-derived suppressor cells as a potential therapy for experimental autoimmune myasthenia gravis. J Immunol. 2014;193:2127-34. [PMID: 25057008; PMCID: PMC4784709. https://doi.org/10.4049/jimmunol.1400857.

30. Kurkó J, Vida A, Ocskó T, Tryniszewska B, Rauch TA, Glant TT, Szekanecz Z, Mikecz K. Suppression of proteoglycan-induced autoimmune arthritis by myeloid-derived suppressor cells generated in vitro from murine bone marrow. PLoS One. 2014;9(11):e111815. [PMID: 25369029; PMCID: PMC4219784. https://doi.org/10.1371/journal.pone.0111815.

31. Chou HS, Hsieh CC, Charles R, Wang L, Wagner T, Fung JJ, Qian S, Lu $\mathrm{L}$. Myeloid-derived suppressor cells protect islet transplants by B7-H1 mediated enhancement of T regulatory cells. Transplantation. 2012; 93(3):272-82. [PMID: 22179405; PMCID: PMC3267010. https://doi.org/ 10.1097/TP.0b013e31823ffd39.

32. Hsieh CC, Chou HS, Yang HR, Lin F, Bhatt S, Qin J, Wang L, Fung JJ, Qian S, Lu L. The role of complement component 3 (C3) in differentiation of myeloid-derived suppressor cells. Blood. 2013; 121(10):1760-8. [PMID: 23299310; PMCID: PMC3591797. https://doi.org/ 10.1182/blood-2012-06-440214.

33. Lechner MG, Liebertz DJ, Epstein AL. Characterization of cytokine-induced myeloid-derived suppressor cells from normal human peripheral blood mononuclear cells. J Immunol. 2010;185(4):2273-84. [PMID: 20644162; PMCID: PMC2923483. https://doi.org/10.4049/jimmunol.1000901.

\section{Ready to submit your research? Choose BMC and benefit from:}

- fast, convenient online submission

- thorough peer review by experienced researchers in your field

- rapid publication on acceptance

- support for research data, including large and complex data types

- gold Open Access which fosters wider collaboration and increased citations

- maximum visibility for your research: over $100 \mathrm{M}$ website views per year

At BMC, research is always in progress.

Learn more biomedcentral.com/submissions 